Background: It has long been recognized that immune-mediated inflammatory diseases, such as rheumatoid arthritis (RA), are prone to coexist with depression due to the effects of cytokines, and that these two illnesses lead to an elevation in patients' pain. However, we often encounter patients with RA who suffer from residual pain despite an improvement in disease activity and inflammation. The specific psychological factors associated with residual pain have not yet been clarified. In addition to the traditional psychological factors, such as depression and anxiety, we focused on pain catastrophizing due to the distortion of pain perception and explored its association with residual pain.

Objectives: To examine whether psychological factors, such as pain catastrophizing, depression, and anxiety, are associated with self-reported pain visual analogue scale (pain-VAS) scores in RA patients with 1 or less on 28joints- swollen/tender counts (SJC/TJC) and CRP.

Methods: This was a cross-sectional study of 290 RA outpatients ( $85 \%$ of whom were women) with scores of less than 1 on SJC, TJC, and CRP, with a median (IQR) age of 66 (57-73) years. The participants completed questionnaires, including pain VAS $(0-100 \mathrm{~mm})$, Pain Catastrophizing Scale (PCS, 0-52 scale), and Hospital Depression and Anxiety Scale (HADS, 0-42 scale). Using linear regression analyses, we analysed whether PC (PCS $\geq 30$ ), depression (HADS-D $\geq 11$ ), and anxiety (HADS-A $\geq 11$ ) (independent variables) were associated with pain VAS scores (dependent variable). After univariate regression analysis, multivariate analysis adjusted for confounding factors was performed.

Results: Patients reported a wide range of pain severity with a median (range) pain VAS score of $9(0-96 \mathrm{~mm})$. The prevalence of anxiety and depression were $5.5 \%$ and $5.9 \%$, respectively. Meanwhile, $24.1 \%$ of the patients experienced pain catastrophizing. Pain catastrophizing was associated with pain VAS scores in univariate and multivariate analyses (Table 1). The presence of anxiety and depression was not associated with pain VAS scores in any model. Multivariate analysis of other covariates showed that age, disease duration, and presence of SJC/TJC of joints other than the 28 joints were positively correlated with pain VAS scores.

Table 1. Univariate and multivariate regression analysis for independent variables associated with pain-VAS scores

\begin{tabular}{|c|c|c|c|c|}
\hline & & Univariate & Multivariate & \\
\hline \multicolumn{3}{|l|}{ independent variables } & Model $1^{*}$ & Model $2^{\star \star}$ \\
\hline \multirow[t]{3}{*}{ Pain catastrophizing } & Estimate & 3.7 & 4.1 & 3.6 \\
\hline & $95 \% \mathrm{Cl}$ & 0.7 to 6.6 & 1.1 to 7.0 & 0.5 to 6.6 \\
\hline & p-value & 0.015 & 0.006 & 0.021 \\
\hline \multirow[t]{3}{*}{ Anxiety } & Estimate & 3.7 & 4.4 & 0.5 \\
\hline & $95 \% \mathrm{Cl}$ & -1.9 to 9.2 & -1.0 to 9.9 & -3.5 to 7.9 \\
\hline & $\mathrm{p}$ value & 0.198 & 0.108 & 0.453 \\
\hline \multirow[t]{3}{*}{ Depression } & Estimate & 3.5 & 4.2 & 3.9 \\
\hline & $95 \% \mathrm{Cl}$ & -1.9 to 8.9 & -1.1 to 9.5 & -1.9 to 8.7 \\
\hline & $p$-value & 0.204 & 0.119 & 0.210 \\
\hline
\end{tabular}

The covariates in multivariate analysis are as follows: age, sex, body mass index, disease duration, Steinbrocker's Stage, prednisolone dosage, biologic agents use, and presence of swollen joint counts/tender joint counts of joints other than the 28 joints. *Model 1: each psychological independent variable and the above covariates. ${ }^{\star \star}$ Model 2: all psychological independent variables and the above covariates.

Conclusion: Pain catastrophizing was associated with pain VAS scores in RA patients with 1 or less on 28joints-SJC/TJC and CRP, emphasising that residual pain in the patients should be treated in a biopsychosocial framework focussing on pain catastrophizing.

Disclosure of Interests: Tamami Yoshida: None declared, Motomu Hashimoto Speakers bureau: Mitsubishi Tanabe Pharma Corporation; Bristol-Myers Squibb; Eisai Co., Ltd.; and Eli Lilly and Company., Grant/research support from: Mitsubishi Tanabe Pharma Corporation; Bristol-Myers Squibb; Eisai Co., Ltd.; and Eli Lilly and Company., Kosaku Murakami Speakers bureau: Eisai Co., Ltd.; Chugai Pharmaceutical Co., Ltd.; Pfizer Inc.; Bristol-Myers Squibb; Mitsubishi Tanabe Pharma Co; UCB Japan Co., Ltd.; Daiichi Sankyo Co., Ltd.; and Astellas Pharma Inc., Consultant of: Eisai Co., Ltd.; Chugai Pharmaceutical Co., Ltd.; Pfizer Inc.; Bristol-Myers Squibb; Mitsubishi Tanabe Pharma Co; UCB Japan Co., Ltd.; Daiichi Sankyo Co., Ltd.; and Astellas Pharma Inc., Koichi Murata Speakers bureau: Eisai Co., Ltd. and Astellas Pharma Inc., Consultant of: Eisai Co., Ltd. and Astellas Pharma Inc., Kohei Nishitani Grant/research support from: Asahi-Kasei Pharma., Ryu Watanabe Speakers bureau: Mitsubishi Tanabe Pharma Co; Pfizer Inc.; Sanofi S.A.; AbbVie GK; Asahi Kasei Pharma; Eisai Co., Ltd.; Eli Lilly and Company; Bristol-Myers Squibb; and Janssen Pharmaceutical K.K., Teruhide Koyama: None declared, Ritei Uehara: None declared, Masao Tanaka Speakers bureau: AbbVie GK, Asahi Kasei Pharma., Astellas Pharma Inc., Ayumi Pharmaceutical Co., Chugai Pharmaceutical Co., Ltd., Eisai Co., Ltd., Eli Lilly Japan K.K., Janssen Pharmaceutical K.K., Mitsubishi Tanabe Pharma Co., Novartis Pharma K.K., Pfizer Inc., Taisyo Pharma., Ltd., UCB Japan Co., Ltd., Grant/research support from: AbbVie GK, Asahi Kasei Pharma., Astellas
Pharma Inc., Ayumi Pharmaceutical Co., Chugai Pharmaceutical Co., Ltd., Eisai Co., Ltd., Eli Lilly Japan K.K., Janssen Pharmaceutical K.K., Mitsubishi Tanabe Pharma Co., Novartis Pharma K.K., Pfizer Inc., Taisyo Pharma., Ltd., UCB Japan Co., Ltd., Hiromu Ito Grant/research support from: Bristol-Myers Squibb, Eisai Co, Taisyo Pharma., and Mochida., Shuichi Matsuda: None declared DOI: 10.1136/annrheumdis-2021-eular.1723

\section{POS1483-HPR A QUANTITATIVE ASSESSMENT OF THE LIKELIHOOD THAT PATIENTS WITH RHEUMATOID ARTHRITIS WILL COMMUNICATE INFORMATION ABOUT RHEUMATOID ARTHRITIS RISK TO RELATIVES}

I. Wells ${ }^{1}$, P. Nightingale ${ }^{2}$, G. Simons ${ }^{1}$, C. Mallen ${ }^{3}$, K. Raza ${ }^{1}$, M. Falahee ${ }^{1}$ ${ }^{1}$ Rheumatology Research Group, University of Birmingham, Birmingham, United Kingdom; ${ }^{2}$ Institute of Translational Medicine, Queen Elizabeth Hospital, Birmingham, United Kingdom; ${ }^{3}$ Primary Care Centre Versus Arthritis, School of Medicine, David Weatherall Building, Keele University, Keele, United Kingdom

Background: First-degree relatives (FDRs) of patients with rheumatoid arthritis (RA) are at increased risk of RA and are being recruited to studies of predictive and preventive approaches. Access to FDRs is usually via the proband with RA. Qualitative investigations have shown that communication of RA risk to FDRs is a complex and selective process. However, quantitative data are needed to develop a robust understanding of this process and its determinants to develop effective communication strategies and support for RA patients and their relatives.

Objectives: To identify predictors of the RA patients' reported likelihood of communicating RA risk information to their FDRs.

Methods: Patients with RA were invited to anonymously complete a survey assessing patient characteristics including age, gender, duration of RA, information seeking and decision making preferences (Autonomy Preference Index ${ }^{1}$ ), interest in FDRs taking a predictive test for RA, dispositional openness, and the general functioning subscale of the McMaster Family Assessment Device ${ }^{2}$ Reported likelihood of communicating RA risk to each of the patients' FDRs was assessed using a Likert scale ranging from extremely unlikely $(0)$ to extremely likely (4). The median score across all FDRs was calculated for each patient. The association between patient characteristics and the median score was examined using univariate approaches.

Results: Surveys were completed by 482 patients (median age 65 years, $72 \%$ female). Most patients reported being likely to communicate RA risk to their FDRs (median score=3). Those who reported their likelihood of communicating RA risk to both children and siblings were more likely to communicate risk to children than siblings $(p<0.001)$. No significant difference was found for FDRs' gender, or patients' gender, on reported likelihood to communicate about RA risk $(p=0.32$ and $p=0.87$, respectively). Patients who were older and who had had RA for longer were less likely to communicate about RA risk with their relatives. Patients who had higher interest in their FDRs taking a predictive test for RA information seeking preferences, openness to communicate, and family functioning were more likely to communicate about risk (Table 1).

Table 1. Descriptive statistics and Spearman's rank-order correlations for the association between patients' characteristics and their median reported likelihood of communicating to their FDRs about RA risk

\begin{tabular}{llll}
\hline Patient characteristics & $\begin{array}{l}\text { Descriptive } \\
\text { statistics }\end{array}$ & $\begin{array}{l}\text { Association with median } \\
\text { likelihood to communi- } \\
\text { cate risk to relatives }\end{array}$ \\
\hline & & Test statistic & P value \\
\hline $\begin{array}{l}\text { Age; median (IQR) } \\
\text { RA duration; median (IQR) }\end{array}$ & $65(55-72)$ & -0.19 & $<0.001^{*}$ \\
$\begin{array}{l}\text { Autonomy preferences } \\
\text { Information seeking; median (IQR) }\end{array}$ & $10(4-20)$ & -0.18 & $0.001^{*}$ \\
$\quad$ Decision making; median (IQR) & $84(75-97)$ & 0.26 & $<0.001^{*}$ \\
$\begin{array}{l}\text { Interest in children taking a test; median } \\
\text { (IQR) }\end{array}$ & $3(2-3)$ & 0.09 & 0.048 \\
$\begin{array}{l}\text { Interest in siblings taking a test; median } \\
\text { (IQR) }\end{array}$ & $2(2-3)$ & 0.44 & $<0.001^{*}$ \\
$\begin{array}{l}\text { Openness; median (IQR) } \\
\text { Family functioning; median (IQR) }\end{array}$ & $2(1-3)$ & 0.44 & $<0.001^{*}$ \\
\hline
\end{tabular}

$p$ values significant at the Bonferroni adjusted value of 0.006 .

Conclusion: Respondents were willing to communicate RA risk to their FDRs, and were more likely to communicate about risk to their children than their siblings. Factors including information seeking preferences, dispositional openness, interest in FDRs taking a predictive test, and family functioning were associated with increased likelihood of communicating RA risk information to FDRs. Patients' age and RA duration were associated with decreased likelihood. These findings increase understanding of communication about RA risk in families, and 
will inform the development of informational approaches to support family communication and access to FDRs.

\section{REFERENCES:}

[1] Ende et al. Journal of General Internal Medicine. 1989; 4(1): 23-30.

[2] Epstein et al. Journal of Marital and Family therapy.1983; 9(2): 171-180. Acknowledgements: This work was supported by Versus Arthritis; Grant reference: 21560 and Riksbankens Jubileumsfond (The Swedish Foundation for Humanities and Social Sciences); Grant reference: M13-0260:1 'Mind the Risk' Disclosure of Interests: Imogen Wells: None declared, Peter Nightingale: None declared, Gwenda Simons: None declared, Christian Mallen Grant/research support from: Keele School of Medicine have received funding to support BMS recruit to a non-pharmacological atrial fibrillation trial., Karim Raza Grant/ research support from: KR reports grants from Abbvie and Pfizer, and personal fees from Abbvie, Pfizer, Sanofi, Lilly, Bristol Myers Squibb, UCB, Janssen, and Roche Chugai, all outside the submitted work., M. Falahee: None declared DOI: 10.1136/annrheumdis-2021-eular.1749

\section{POS1484-HPR THE ASSOCIATION OF STIGMA WITH DISEASE VARIABLES IN PATIENTS WITH FIBROMYALGIA (FM)}

M. Offenbächer ${ }^{1}$, L. Toussaint ${ }^{2}$, M. Weigl ${ }^{3}$, J. Dezutter $^{4}$, N. Kohls ${ }^{5}$, M. Vallejo ${ }^{6}$ J. Rivera ${ }^{7}$, F. Sirois ${ }^{8}$, J. Hirsch ${ }^{9} .{ }^{1}$ Gasteiner Heilstollen, Medical Department, Bad Gastein, Austria; ${ }^{2}$ Luther College, Psychology, Decorah, United States of America; ${ }^{3}$ University Hospital, Department of Orthopaedics, Physical Medicine and Rehabilitation, München, Germany; ${ }^{4}$ University of Leuven, School Psychology and Development in Context, Leuven, Belgium; ${ }^{5}$ Coburg University of Applied Sciences, Health Promotion, Coburg, Germany; ${ }^{6}$ UNED, Psychology, Madrid, Spain; ${ }^{7}$ Gregorio Marañón Hospital, Rheumatology, Madrid, Spain;

${ }^{8}$ The University of Sheffield, Psychology, Sheffield, United Kingdom; ${ }^{9}$ East

Tennessee State University, Psychology, Johnson City, United States of America

Background: Stigma, defined as social devaluation of an individual, can be an important stressor for chronic pain patients [1]. Not every condition is stigmatized. A relevant factor for illness stigmatization seems to be whether the cause is mental-behavioural or physical. Chronic pain is often regarded as an imaginary illness or caused by psychological problems [2]. Sources of stigma for chronic pain patients are perceived negative attitudes from family members, the general public, and physicians [1].. Objectives: To assess perceived stigma and the associations with disease variables in a cohort of patients with FM.

Methods: We invited 18 FM self-help groups in Germany to participate anonymously in our survey, and we sent the survey battery to 192 potential participants via postal mail. To measure perceived stigma, we used the Chronic Pain Stigma Scale (CPSS) developed by Reed [3], which has 30 items and 3 subscales (public, physicians, family). We also assessed sociodemographic characteristics, disease related variables (e.g., pain, stress, depression, anxiety), and other health-related factors, including health related quality of life [Healthy Days Core Module (CDC HDQOL-4)], disease specific impact (FIQ), fear avoidance belief questionnaire (physical activity subscale) (FABQ-PA), pain catastrophizing scale (PCS) and pain self-efficacy questionnaire (PSEQ).

Results: In total $162 \mathrm{FM}$ patients participated (=84\% response rate). Their mean age was 58 years $(S D=10), 84 \%(N=135)$ were female. Highest level of education was: Elementary School 29\%, Junior High School 35\%, High School 15\%, College 12\%, and other $10 \%$. Duration of chronic pain was 18.2 years $(S D=12.0)$. There was no significant gender difference in the stigma subscales, nor was there an association with duration of chronic pain. Table 1 presents the significant Pearson correlations.

Table 1. Correlations of CPSS stigma subscales with health variables. ${ }^{\star}<.05 ;{ }^{* *}<.01$; ns=not significant.

\begin{tabular}{|c|c|c|c|}
\hline & CPSS-public & CPSS-physician & CPSS-family \\
\hline Regional pain scale & ns & $.19^{*}$ & $.20^{\star}$ \\
\hline VAS pain today & ns & ns & Ns \\
\hline $\mathrm{FIQ}$ & $.20^{*}$ & $.16^{*}$ & $.22^{\star \star}$ \\
\hline HADS-anxiety & $.37^{\star}$ & $.20^{*}$ & $.24^{\star}$ \\
\hline HADS-depression & $.41^{\star \star}$ & $.16^{\star}$ & $.25^{\star \star}$ \\
\hline \multicolumn{4}{|l|}{ CDC-HDQOL-4 } \\
\hline General health & $.19^{*}$ & $.18^{*}$ & $.22^{\star \star}$ \\
\hline Physical health & $.19^{\star}$ & ns & ns \\
\hline Mental health & $.20^{\star}$ & ns & $.21^{*}$ \\
\hline Impairment & $.24^{\star}$ & ns & ns \\
\hline Perceived stress scale & $.44^{\star \star}$ & $.24^{\star \star}$ & $.37^{\star \star}$ \\
\hline FABQ-PA & ns & $-.17^{\star}$ & ns \\
\hline PCS & $.21^{*}$ & ns & ns \\
\hline PSEQ & $.19^{\star}$ & ns & $.18^{*}$ \\
\hline
\end{tabular}

Conclusion: Perceived stigma in our FM patient cohort has an important impact on a variety of different disease variables including mental and general health, physical functioning, and on pain coping. Stigmatizing attitudes perceived from the general public exhibited the greatest association with most variables in our chronic pain patients. Perceived stigma from physicians and the family were also related to negative disease consequences in our FM patients. To conclude, we assert that assessing and addressing multi-source perceived stigmatization in routine clinical care may improve the management and wellbeing of patients with FM.

\section{REFERENCES:}

[1] Waugh OC, Byrne DG, Nicholas MK. Internalized stigma in people living with chronic pain. J Pain 2014;15(5):550 e1-10.

[2] Werner A, Isaksen LW, Malterud K. 'I am not the kind of woman who complains of everything': illness stories on self and shame in women with chronic pain. Soc Sci Med 2004;59(5): 1035-45

[3]Reed P. Chronic pain stigma: developement of the Chronic Pain Stigma Scale. 2005

Disclosure of Interests: None declared

DOI: 10.1136/annrheumdis-2021-eular.1974

\section{POS1485-HPR PATIENTS' PERSPECTIVE ON CONTINUATION VERSUS TEMPORARY INTERRUPTION OF IMMUNOMODULATORY AGENTS DURING INFECTIONS IN PATIENTS WITH IMMUNE-MEDIATED INFLAMMATORY DISEASES: AN INTERVIEW STUDY}

M. Opdam ${ }^{1}$, L. M. Verhoef ${ }^{1}$, J. Vriezekolk ${ }^{1}$, B. Van den Bemt ${ }^{2,3}$, A. Den Broeder ${ }^{1} .{ }^{1}$ Sint Maartenskliniek, Rheumatology, Ubbergen, Netherlands; ${ }^{2}$ Sint Maartenskliniek, Pharmacy, Ubbergen, Netherlands; ${ }^{3}$ Radboud University Medical Center, Pharmacy, Nijmegen, Netherlands

Background: Immune mediated inflammatory diseases (IMIDs) like rheumatoid arthritis (RA) are often treated with immunomodulatory agents (IA). Infection risks appear to be slightly increased in IMID patients using IA ${ }^{1}$. However, it remains uncertain whether it is best to continue or temporary interrupt IA in case of an infection For this decision, it is essential to know patient's perceptions about both strategies. Unfortunately, little is known about the patients' perceptions on this topic. Objectives: To explore the patients' perspectives on continuation and temporary interruption of IA in case of an infection and assess possible barriers and facilitators. Methods: Semi-structured interviews were conducted in IMID patients using IA Patients were recruited from the rheumatology, dermatology and gastroenterology departments of two hospitals in the Netherlands. Purposive sampling was used to select a diverse patient population. Semi-structured interviews were performed until data saturation was reached and analyzed using inductive thematic analysis. Results: 19 patients with 6 different IMIDs and 17 different IA were interviewed. The majority was female, mean age 51 years and mean disease duration 17 years. Four had experienced a severe infection (requiring hospitalization). 15 patients indicated that they would prefer to continue their IA in case of an infection, however, for most patients this would depend on the infection severity. Several facilitators and barriers were identified (Table 1). Patients mentioned disease flare as a barrier for temporary interruption. Beliefs about susceptibility to infections form barriers and facilitators for both temporary interruption and continuation. Patients also mentioned that they would follow their physician's advice on continuation/temporary interruption.

Table 1. Identified barriers and facilitators

Temporary interruption

Barriers

Disease flare and its impact

Loss of IA effects or increased side effects after restarting

Long duration of interruption

Belief: IA has no/a positive effect on infection (risk)

Belief: not more susceptible for infections

Practical barriers

Not aware of possibility of interruption

Not following physician's advice

More severe and/or longer lasting infection

Interactions with medication needed for infection

Positive effect of interruption on immune system

Short duration of interruption

Belief: more susceptible for infections

Belief: IA has a negative effect on infection (risk)

Concerned about infections

Current stable disease

Physician's advice

Long duration of IA effects

Wish to taper/stop IA in general

Negative impact of infection on daily activities

Continuation

Barriers

Belief: more susceptible for infections

Belief: IA has a negative effect on infection (risk)

Negative previous experiences during infection

Loss of IA effects after long use

Interactions with medication needed for infection

Belief: not more susceptible for infections

Belief: IA has no/a positive effect on infection (risk)

Not concerned about infections

IA needed to control IMID

Mild infection

Positive previous experiences with continuation

Physician's advice 